\title{
Políticas públicas para educação de jovens e adultos no Brasil: a permanente (re)construção da subalternidade - considerações sobre os Programas Brasil Alfabetizado e Fazendo Escola*
}

\section{Public policy for youth and adult education in Brazil: non-commission permanent (re)building - considerations about Literate Brazil and Doing School Programs}

\author{
Sonia Maria Rummert ${ }^{* *}$ \\ Jaqueline Pereira Ventura ${ }^{* * *}$
}

\begin{abstract}
RESUMO
A problemática relativa à Educação de Jovens e Adultos (EJA), no âmbito do Estado brasileiro, tem se tornado significativamente mais complexa na última década. Tal complexidade deriva dos processos de correlação de forças emergentes na atual fase de expansão e consolidação do capital, entre os quais se destaca a implantação de políticas neoliberais que deu origem, por exemplo, à reforma do Estado e às estratégias de reestruturação produtiva.
\end{abstract}

* Este artigo apresenta resultados parciais da pesquisa Educação básica e profissional de trabalhadores. Políticas públicas e ações do Estado, do Trabalho e do Capital, apoiada pelo $\mathrm{CNPq}$, na qual se inscreve o trabalho de elaboração da Tese de Doutorado Educação de Jovens e Adultos ou educação da classe trabalhadora? Projetos de formação, concepções em disputa, empreendido por Jaqueline P. Ventura.

** Doutora em Educação (PUC-RJ). Professora Associada da Faculdade de Educação da Universidade Federal Fluminense e Bolsista de Produtividade do CNPq. E-mail: rummert@uol.com.br.

**** Mestre em Educação (UFF). Supervisora Pedagógica da FME-Niterói/RJ e doutoranda do Programa de Pós-Graduação em Educação da UFF, com bolsa do CNPq. E-mail: jaqventura@uol.com.br. 
No presente artigo, pretendemos evidenciar que os atuais programas para a Educação de Jovens e Adultos trabalhadores desenvolvidos pelo Ministério da Educação (MEC) representam rearranjos da mesma lógica que sempre presidiu as políticas para a Educação de Jovens e Adultos no Brasil, a qual consiste em atender às necessidades de sociabilidade do próprio capital. Desta forma, as políticas educativas com caráter compensatório e aligeirado reiteram, a partir de reordenamentos econômicas dos quais derivam o desemprego estrutural e novas formulações ideológicas centradas no empreendedorismo e na empregabilidade, a subalternidade das propostas de educação para a classe trabalhadora. Neste texto serão abordados os programas Brasil Alfabetizado e Fazendo Escola no conjunto das políticas de governo para a educação, procurando-se evidenciar o quanto esse tipo de política reafirma o caráter seletivo e excludente do sistema público educacional no Brasil.

Palavras-chave: educação de jovens e adultos; políticas educacionais; trabalho e educação.

\begin{abstract}
The problematic related to youth and adult education (EJA Program) had got significative relevance in Brazilian State scope. Such complexity is derivative of the emergent growth process of correlated forces in present level of capital expansion and consolidation; these processes show up neoliberal policy implantation, which originated, for example, State reform and productive structural rebuilding strategies. This article intends to show up that current programs developed by the Education Ministry (MEC) for working youth and adult education represent reorganization of the same logic that always guided youth and adult education policy in Brazil; a policy that consists in sociability necessity of capital itself. Thus, compensatory and superficial education policies reinforces non-commission of educational proposals for working class by economical reorganization that produces structural unemployment and new ideological formulations centered on enterprising and employment. This text focuses Literate Brazil Program as well as Doing School Program inside the complex of govern policy for education, intending to clear up how much such policy reasserts selective and excluding characteristics of Brazilian public education system.

Key-words: youth and adult education; educational policy; work and education.
\end{abstract}




\section{A EJA nos anos 1990 e 2000: a subalternidade reiterada}

Nas duas últimas décadas, empreendeu-se, no Brasil, um processo de reformas da matriz neoliberal que resultou na desconstrução dos compromissos ético-políticos e sociais firmados pelo Estado na Constituição de 1988. Tal processo correspondeu às demandas para a inserção do país, de forma associada e subalterna, no atual quadro hegemônico mundial. É, assim, nos marcos da nova ordem econômica internacional e de adaptação do Estado brasileiro à concepção de estado mínimo, que é empreendida a reforma educacional brasileira na década de 1990. Combinando centralização das decisões com descentralização das ações e das responsabilidades de execução, a Lei de Diretrizes e Bases da Educação Nacional (LDB 9.394/ 96) e demais instrumentos legais imprimiram às políticas públicas, no âmbito da educação, o tom acentuadamente pulverizado e compensatório. Tal lógica, que orienta as políticas educacionais, redefiniu também o financiamento público e o conteúdo da ação governamental, passando a priorizar estratégias de focalização em grupos de extrema pobreza. É no bojo dessa problemática que se situam as atuais políticas destinadas à educação dos jovens e adultos trabalhadores, como procuraremos explicitar ao longo do presente artigo.

A Constituição Brasileira de 1988 reconheceu o direito de todos à educação, ao afirmar o ensino fundamental, obrigatório e gratuito, independentemente da idade. Entretanto, nos anos de 1990, a LDB 9.394/96, o Fundo de Manutenção e Desenvolvimento do Ensino Fundamental e Valorização do Magistério (FUNDEF) e a reforma da Educação Profissional, por meio do Decreto 2.208/97, redefiniram os rumos da política educacional, o que significou expressivo retrocesso no âmbito da Educação de Jovens e Adultos (EJA). Acentuou-se, então, o lugar secundário ocupado pela EJA no conjunto das políticas educacionais.

Por um lado, a nova LDB incorporou uma mudança conceitual ao substituir a denominação Ensino Supletivo por Educação de Jovens e Adultos, avaliada de forma positiva por profissionais da área. Para Soares:

A mudança de ensino supletivo para educação de jovens e adultos não é uma mera atualização vocabular. Houve um alargamento do conceito ao mudar a expressão de ensino para educação. Enquanto o termo "ensino" se restringe à mera instrução, o termo "educação" é muito mais amplo, 
compreendendo os diversos processos de formação (SOARES, 2002, p. 12).

Por outro lado, o corpo do texto continuou referindo-se a "cursos e exames supletivos" (Art. 38), perpetuando, portanto, a concepção de suplência, de correção de fluxo escolar e de compensação. A redução das idades mínimas para a realização de exames supletivos, de 18 para 15 anos no Ensino Fundamental e de 21 para 18 anos no Ensino Médio, constituiu uma mudança significativa que corroborou a desqualificação desta modalidade de ensino e da própria escola, uma vez que se privilegiou a idade mínima para a certificação em detrimento dos processos pedagógicos sistemáticos. Em oposição ao breve tratamento dado à EJA, a LDB reservou espaço mais destacado para a Educação Profissional, embora, também de forma sintomática, tenha estabelecido distinções claras entre a Educação Profissional e a Educação Superior, abordadas separadamente no instrumento legal.

Também as novas regras do financiamento concorreram para secundarizar a EJA ao desestimular a criação ou mesmo a ampliação de turmas na educação de jovens e adultos nos Estados e Municípios. O FUNDEF, também datado de 1996, não incluiu os alunos que cursavam o Ensino Fundamental no então denominado ensino supletivo no cômputo de matrículas para o repasse dos recursos desse fundo. Tal restrição acarretou, em significativo número de municípios brasileiros, a redução da oferta de vagas no supletivo, substituído pelo regular noturno, cujas matrículas eram contabilizadas nos cálculos do FUNDEF, sem que ocorresse nenhuma adaptação de caráter pedagógico com vistas a atender às especificidades dos jovens e adultos.

Do mesmo modo, o Decreto $\mathrm{n}^{\circ} 2.208 / 97$, que propiciou a chamada nova institucionalidade da educação profissional, concorreu para reiterar a desqualificação da EJA. Ao subdividir em níveis independentes a formação profissional, sendo o primeiro o nível básico, desvinculado de qualquer nível de escolaridade mínimo, o Decreto concorreu para gerar o campo propício para a oferta de cursos aligeirados de formação profissional que pouco, ou nada, acrescentavam à formação plena dos jovens e adultos trabalhadores ${ }^{1}$.

1 O Art. $3^{\circ}$ do Decreto 2.208/97 redefine em três níveis a formação profissional, a saber: I - básico, II - técnico e III - tecnológico (BRASIL, 1997). 
Essa nova institucionalidade e o que dela decorreu no âmbito da EJA acentuou, de forma significativa, o desenho de uma "divisão de tarefas" entre o Ministério da Educação e o do Trabalho e Emprego. Este último, utilizando recursos do Fundo de Amparo ao Trabalhador (FAT), ofertou a educação profissional de nível básico, em geral com cursos instrumentais, de curta duração e desvinculados da escolaridade a uma parcela significativa das frações mais fragilizadas da classe trabalhadora. Como conseqüência, o atendimento às demandas por educação da população adulta de baixa escolaridade passa a ser realizado por meio da criação de uma rede de cursos de qualificação profissional, cabendo seu financiamento ao Ministério do Trabalho e Emprego e a tarefa de execução a diversas instituições da sociedade civil, como empresas, ONGs, entidades sindicais representativas dos trabalhadores, o Sistema $\mathrm{S}$, entre outras ${ }^{2}$.

Em 2004, novo Decreto, de número $5.154^{3}$, revoga o anterior sem, contudo, instituir mudanças substantivas na organização da educação profissional. Como assinala Rodrigues (2005), “o decreto apenas reconhece (ou naturaliza) os diferentes projetos político-pedagógicos, clivados pela dualidade estrutural social, presentes na sociedade de classes em que vivemos". Desta forma, dispersa em diferentes órgãos governamentais, realizada sob a forma dos mais variados programas e projetos, uma "nova" identidade da EJA vai se forjando na década de 1990. Passa a apresentar-se de forma mais ampla, mais fragmentada e mais heterogênea. Tais características, entretanto, não alteram sua marca histórica: ser uma educação política e pedagogicamente frágil, fortemente marcada pelo aligeiramento, destinada, predominantemente, à correção de fluxo e à redução de indicadores de baixa escolaridade e não à efetiva socialização das bases do conhecimento. E comprometida com a permanente construção e manutenção da hegemonia inerente às necessidades de sociabilidade do próprio capital $\mathrm{e}$ não com a emancipação da classe trabalhadora.

O período compreendido entre 2003 e 2006, referente ao primeiro governo de Luiz Inácio Lula da Silva, traz para a EJA um maior destaque do que o obtido nos governos anteriores da Nova República. Entretanto, se há

2 Nesse período, o Plano Nacional de Formação Profissional (PLANFOR) foi emblemático da concepção de educação que estava sendo desenhada. Para uma análise da relação entre a EJA e o PLANFOR, ver Ventura, 2001.

3 Segundo o Art. $1^{\mathrm{o}}$ : I - formação inicial e continuada de trabalhadores; II - educação profissional técnica de nível médio; e III - educação profissional tecnológica de graduação e pós-graduação (BRASIL, 2004). Sobre o debate acerca deste decreto, consultar: Rodrigues (2005) e Frigotto; Ciavatta; Ramos (2005). 
um discurso que anuncia sua valorização, esse não se faz acompanhar de ações concretas para a superação da matriz construída na década anterior. Assim, embora vejamos ampliado o arco de ações no âmbito da EJA, o mesmo permanece centrado nas políticas focais, fragmentadas e fragmentadoras do tecido social. Nelas se verifica a clara difusão da falsa premissa de que, como assinalou Marx (1984), a força de trabalho, tomada como mercadoria, é capaz, ela própria, de ampliar suas possibilidades de exploração pelo capital.

É inegável que, no período, a EJA tornou-se objeto de um número bem mais significativo de iniciativas do que anteriormente, as quais, entretanto, se apresentam como claras explicitações do quadro já delineado. A centralidade de tais ações reside na ampliação de mecanismos de certificação, relativos à conclusão do Ensino Fundamental, à formação profissional particularmente a de caráter inicial, como já mencionado, e, com menor ênfase, ao término do Ensino Médio. Entre essas iniciativas, podem ser destacados o Projeto Escola de Fábrica, o Programa Nacional de Inclusão de Jovens - PROJOVEM - e o Programa de Integração da Educação Profissional ao Ensino Médio para Jovens e Adultos - PROEJA ${ }^{4}$. Além desses, merecem destaque o Programa Brasil Alfabetizado e, também, o Fazendo Escola, ambos implementados pela Secretaria de Educação Continuada, Alfabetização e Diversidade - SECAD, em cuja breve descrição e análise nos deteremos a seguir.

\section{O Programa Brasil Alfabetizado}

Implementado em 2003, para "erradicar" o analfabetismo no Brasil, esse programa tem por finalidade "capacitar alfabetizadores e alfabetizar cidadãos com 15 anos ou mais que não tiveram oportunidade ou foram excluídos da escola antes de aprender a ler e escrever"s. Segundo o Ministério da Educação, o período estipulado para e alfabetização é de até oito meses, com uma carga horária estimada entre 240 e 320 horas. Segundo os documentos oficiais, o programa atua sob a forma de transferência de

4 Acerca desses projetos, ver, por exemplo, Rummert (2005, 2007).

5 Disponível em: <www.mec.gov.br>. Acesso em maio de 2006. 
recursos financeiros aos estados e municípios, bem como a empresas privadas, universidades, organizações não-governamentais e instituições civis, considerados parceiros no processo ${ }^{6}$. A assistência financeira concedida permite a execução de duas ações: a formação de alfabetizadores e a alfabetização de jovens e adultos. Pelos termos do convênio, as instituições são responsáveis pela cessão do espaço (salas de aula), pela formação dos educadores e cadastramento dos alunos e professores. Não há destinação de recursos para material didático, alimentação ou qualquer apoio pedagógico, que, quando existem, são considerados como contrapartida da entidade parceira.

Apesar de gradualmente o Programa vir incorporando as críticas e sendo reformulado, ainda são muitas as semelhanças que guarda com relação a outras iniciativas tomadas com o mesmo objetivo ao longo das seis últimas décadas. Em sua primeira fase, eram evidentes muitas semelhanças com o que o precedeu durante o governo de Fernando Henrique Cardoso, o Programa Alfabetização Solidária (PAS) ${ }^{7}$.

O lançamento, em 2003, do programa Brasil Alfabetizado, com a apresentação de uma proposta nos moldes de campanha, desvinculada da educação básica, não superando o viés das ações anteriores, deixou os educadores progressistas perplexos pela recorrência do equívoco. Questionavase, desde o início, seu caráter de campanha, as bases de sua concepção, análogas às de tantas iniciativas fracassadas já implementadas em outros períodos históricos - como o MOBRAL e o PAS - e a desconsideração de amplo conjunto de trabalhos que evidenciam as fragilidades e limites de tais

6 Nos primeiros anos, o repasse de recursos financeiros do Brasil Alfabetizado era realizado por meio de convênios, indistintamente realizados com as secretarias de educação ou instituições interessadas. Atualmente, o repasse de recursos é regulamentado por critérios diferenciados, estabelecidos pela Resolução CD/FNDE n. ${ }^{\circ}$ 022, de 20 de abril de 2006 e pela Resolução CD/FNDE n. ${ }^{\circ}$ 031, de 10 de agosto de 2006.

7 O PAS foi criado em 1996, pelo Conselho da ONG Comunidade Solidária, vinculada à Casa Civil da Presidência da República, com o objetivo de coordenar ações sociais emergenciais de combate à pobreza. O Programa foi concebido como campanha de alfabetização a ser desenvolvida com parcerias entre os poderes públicos federal e municipal, organizações da sociedade civil, empresas, fundações e instituições de ensino superior públicas e privadas. Os recursos financeiros para o custo do aluno no PAS eram compartilhados entre o governo federal e as empresas, que podiam selecionar os municípios a serem apoiados. $\mathrm{O}$ MEC contribuía com $50 \%$ do custo-aluno no PAS e, nos municípios com IDH (Índice de Desenvolvimento Humano) inferior a 0,5 e que não fossem "adotados" por parceiros privados, o governo assumia o custo do projeto. Pode-se dizer que o PAS simboliza a consolidação da tendência à descentralização, tendo por objetivo empreender ações sociais de combate a situações de extrema pobreza. 
iniciativas. Diálogos entre a SECAD e especialistas da área, ao longo do período de implementação do Brasil Alfabetizado, resultaram em algumas alterações no Programa. Entretanto, os ajustes e tentativas de acerto têm se limitado a aprimoramentos de uma mesma lógica, sem que se rompa com os fundamentos da concepção de programa emergencial que o estrutura ${ }^{8}$.

Assim, mesmo considerando os ajustes, o formato do Programa permite que continuem a ser destinados recursos públicos a instituições privadas, o que implica, coerentemente com as teses de redução da presença direta do Estado na área social, a ausência de compromisso com a consolidação da EJA nos sistemas públicos de ensino. Além disso, desvincula as ações de alfabetização da Educação de Jovens e Adultos, posto não haver políticas públicas que assegurem articulação efetiva entre a fase de mobilização - representada pela alfabetização - e a de continuidade, a qual deveria assegurar o acesso universal dos jovens e adultos ao Ensino Fundamental e Médio na modalidade da EJA. Destaca-se, ainda, o fato de que as ações de alfabetização abrigadas pelo Programa, por serem pulverizadas, sobrepostas e heterogêneas, reforçam um conjunto de práticas que se coadunam com as marcas de diferentes formas de precarização a que estão, em geral, submetidos alfabetizadores e alunos.

Uma vez que os limites deste trabalho não possibilitam uma análise detalhada do Programa, podemos nos ater a dados recentemente divulgados que corroboram as críticas a ele formuladas. Recebido com grande repercussão pela mídia ${ }^{9}$, o Brasil Alfabetizado, como as iniciativas anteriores, foi apresentado pelos discursos dominantes como a via de solução para o analfabetismo que, no início do Século XXI, ainda atingia aproximadamente 15 milhões de brasileiros. Constituiu-se, assim, em mais um entre muitos processos de distribuição de ilusões relativas ao âmbito da educação empreendido pelas forças dominantes em atendimento à permanente necessidade de construção e manutenção de hegemonia.

Entretanto, ao final do ano de 2006, a mesma mídia, embora com menor ênfase, nos oferece informações que evidenciam a procedência da

8 Dentre as reformulações, segundo o MEC, destacam-se: a ampliação do período de alfabetização (de seis para oito meses); aumento nos recursos para a formação dos alfabetizadores; estabelecimento de um piso para a bolsa do alfabetizador; implantação de um sistema integrado de monitoramento e avaliação do Programa; e aumento do percentual de recursos para estados e municípios para que façam a inserção dos alfabetizados nos sistemas de ensino, mudanças nos critérios e procedimentos para a distribuição dos recursos financeiros (conforme http://portal.mec.gov.br/secad/, acesso em março de 2007).

9 As notícias sobre o Brasil Alfabetizado, veiculadas no período de 2003 a 2006, podem ser encontradas em http://www.uff.br/ejatrabalhadores. 
abordagem desfavorável acerca do Programa. Dados apresentados pelo IBGE/PNAD 2005 (IBGE, 2006) demonstravam o fato de que, dois anos após a implementação da nova "campanha", e tendo sido gastos um total aproximado de R\$330 milhões no biênio 2003-2005, a queda percentual no número de analfabetos absolutos situou-se no reduzido patamar de $0,3 \%{ }^{10}$.

Compreender as razões que dão origem a tais indicadores exige que nos debrucemos sobre um conjunto de variáveis que transcendem o âmbito do próprio Programa. Considerar a decisiva importância do contexto socioeconômico e cultural dos jovens e adultos da classe trabalhadora e reconhecer o caráter decisivo da ampliação dos processos de produção cada vez mais precária da existência é um procedimento teórico-metodológico que se impõe se pretendemos, efetivamente, alterar o quadro que os próprios órgãos oficiais nos apresentam. Tal alteração exige, portanto, mudanças de caráter profundo no próprio modelo societário, a serem empreendidas de forma integrada com novas e necessárias concepções e práticas no âmbito da educação, o que não parece estar no horizonte do atual governo que inicia seu segundo mandato.

\section{Programa Fazendo Escola}

O Programa de Apoio aos Sistemas de Ensino para atendimento à Educação de Jovens e Adultos - Fazendo Escola, instituído em 2003 ${ }^{11}$, apresenta como objetivo "contribuir para enfrentar o analfabetismo e baixa escolaridade em bolsões de pobreza do País onde se concentra a maior parte da população de jovens e adultos que não completou o Ensino Fundamental" (www.mec.gov.br/secad; acesso em janeiro de 2006). O programa "é desenvolvido pelo MEC em conjunto com os governos estaduais e municipais, por meio da transferência, em caráter suplementar, de recursos administrados pelo FNDE" (www.fnde.gov.br/home/index.jsp?arquivo=/ eja_edujovadult/eja.html).

${ }^{10}$ Ver, por exemplo: http://www1.folha.uol.com.br/folha/educacao/ult305u19328.shtml e http://txt.estado.com.br/editorias/2006/09/17/pol-1.93.11.20060917.6.1.xml.

${ }^{11}$ Resolução CD/FNDE/05, de 02 de abril de 2003. 
Ainda de acordo com as fontes governamentais, a transferência dos recursos do Programa é proporcional ao número de alunos matriculados, conforme informado no censo escolar do ano anterior ao dos repasses. O valor aplicado anualmente é de, no máximo, R\$ 250,00 por aluno ${ }^{12}$. Os recursos repassados podem ser utilizados para contratação/remuneração e formação continuada dos docentes, aquisição/impressão de material didático, fornecimento de material escolar e compra de gêneros alimentícios para os alunos.

Embora no formato atual o Programa date de 2003, para compreender sua lógica é necessário retroceder ao Programa Recomeço, compreendendo sua relação com o FUNDEF. Com a exclusão da EJA dos recursos financeiros do FUNDEF, como anteriormente referido, a modalidade permaneceu praticamente sem recursos da União até 2001, quando foi criado o Programa Recomeço ${ }^{13}$. Financiado com recursos do Fundo de Amparo à Pobreza, criado em 2000 no Governo Fernando Henrique Cardoso para financiar projetos de assistência social, o Programa Recomeço tinha duração prevista de 2001 a 2003 e consistia na transferência de recursos financeiros aos estados e municípios selecionados. O objetivo deste programa era contribuir para enfrentar o analfabetismo e a baixa escolaridade dos bolsões de pobreza do país. Também cabe considerar que o Recomeço integrou o Projeto Alvorada ${ }^{14}$, responsável por articular programas sociais, de infra-estrutura e desenvolvimento focados na redução das desigualdades regionais e melhoria das condições de vida nos locais mais pobres do Brasil, identificados a partir do seu IDH.

12 Nos quatro anos de vigência, o FNDE informa que foram aplicados os seguintes montantes anuais de recursos: 2006: R\$ 412 milhões, 2005: R\$ 460 milhões, 2004: R\$ 420 milhões, 2003: R\$ 387 milhões (Conforme http://www.fnde.gov.br/home/index.jsp?arquivo=/ eja_edujovadult/eja.html\#dadosesta).

${ }^{13}$ Merece destaque o fato de que o Programa Recomeço (Resolução FNDE/CD/12, de 26 de abril de 2001) foi criado logo após a aprovação do Parecer CNE/CEB 11/2000; consideramos pertinente indicar a possível influência desse Parecer na decisão do Governo Federal em, por meio do FNDE, "contribuir para a educação de jovens e adultos" (grifo nosso), determinando, na Resolução $\mathrm{FNDE} / \mathrm{CD} / 12 / 01$, a "assistência financeira suplementar a projetos educacionais no âmbito da EJA", prioritariamente, aos estados das Regiões Norte e Nordeste, onde se desenvolvia o Projeto Alvorada.

${ }^{14}$ O Projeto Alvorada tinha, segundo seus documentos, o objetivo de "criar condições necessárias para reduzir a pobreza e as desigualdades regionais do país, proporcionando a cada cidadão oportunidades de trabalho e acesso aos bens e serviços. Para alcançar tal objetivo, o projeto reservava recursos para as regiões com maiores necessidades dos estados mais carentes" (http://portal.web02.saude.gov.br, acesso em novembro de 2004). 
Além da mudança das denominações, ressalta-se que, de início, não houve alteração na proposta, nos municípios atendidos ou no valor do repasse financeiro realizado pela União. Em 2004, a alteração constituiu na criação de um segundo critério de atendimento que estendia o apoio, por meio de transferência direta de recursos, às redes de ensino que participaram do Programa Brasil Alfabetizado, visando com isso estimular as secretarias de educação a assumirem a continuidade do Ensino Fundamental aos alunos que tivessem participado do Programa. Convém destacar que o Programa Fazendo Escola é considerado pelo MEC como transitório, devendo ser encerrado a partir da aprovação do novo fundo da Educação Básica, o FUNDEB. Entretanto, o FUNDEB, da forma como vem sendo encaminhado, nos parece também insuficiente para atender à demanda social referente à EJA, uma vez que, mesmo que a modalidade seja incluída, nas formulações até agora apresentadas ainda vigora a premissa de qu,e o valor/aluno da EJA pode ser inferior àquele destinado aos demais alunos da educação básica.

Novas mudanças nos critérios para a distribuição dos recursos financeiros para o Programa Fazendo Escola ocorrem em 2005. Na nova proposta, todos os municípios que registravam alunos matriculados na EJA passam a receber algum recurso ${ }^{15}$. Entretanto, tal repasse passa a assumir valores diferenciados, estabelecidos de acordo com um novo índice criado - IFEJA, Índice de Fragilidade Educacional de Jovens e Adultos -, a partir do qual se passa a definir os valores repassados aos municípios ${ }^{16}$. O que se deve destacar nesse processo é o fato de que o Ministério da Educação, por meio do FNDE, cria uma fórmula para ampliar o "apoio aos sistemas de ensino para atendimento à EJA" a todos os estados e municípios do Brasil sem que isso signifique a ampliação dos recursos destinados à EJA.

Apesar do anúncio de que se pretende, por meio do Programa Fazendo Escola, institucionalizar a Educação de Jovens e Adultos como política pública no sistema de ensino brasileiro, ao considerar o conteúdo do Programa e dos seus mecanismos de financiamento, a viabilidade prática desse enunciado nos parece bastante difícil. Em recente pesquisa, solicitada pela

15 Resolução CD/FNDE no 25, 16 de junho de 2005.

${ }^{16}$ O IFEJA é calculado "a partir dos índices de analfabetismo da população com 15 anos ou mais, de analfabetismo funcional (IBGE/2000) e da população com 25 anos ou mais com menos de oito anos de estudo; a partir destes dados, foram definidos oito coeficientes de diferenciação para o repasse de recursos". Informações mais detalhadas podem ser obtidas em http://www.fnde.gov.br: Educação de Jovens e Adultos (acesso em fevereiro de 2007). 
SECAD para a realização de uma avaliação do Programa Fazendo Escola, destacou-se o fato de que, entre dez municípios pesquisados, apenas dois conheciam o Programa Fazendo Escola e só um, de fato, desenvolvia uma política articulada e de integração dos entes federados para a oferta de EJA. Nossos estudos apontam, novamente, para o fato de que este formato de Programa, herdado de gestões anteriores e adotado pelo atual Governo Federal, ainda é insuficiente para a construção de políticas públicas sólidas para a educação de jovens e adultos.

\section{Novos programas, velhas concepções de educação para a classe trabalhadora}

Ao buscar a origem e os pressupostos dos "novos" programas para a educação de jovens e adultos desenvolvidos pelo MEC, entre os quais se destacam os eleitos para análise no presente trabalho, o Brasil Alfabetizado e o Fazendo Escola, o estudo evidencia que estes programas caracterizamse por ser mais um rearranjo do mesmo pensamento hegemônico que tem gerado, ao longo da história, um conjunto de propostas com vistas a atender, prioritariamente, às necessidades do capital nos países periféricos ou semiperiféricos. O caráter de amenização das tensões sociais e dos impasses inerentes à lógica do sistema parece ser uma das funções cumpridas, atualmente, por diferentes programas destinados a jovens e adultos trabalhadores, como vimos, ainda hoje sem lugar próprio no cenário educacional brasileiro.

Observa-se que os baixos níveis de escolaridade da população continuam sendo tratados de forma secundarizada, com ações descontínuas e, predominantemente, resumidas às iniciativas de alfabetização. Pode-se afirmar, nesta fase ainda preliminar dos estudos, que a lógica que preside ambos os programas reedita o mesmo viés discriminatório que tem orientado essa modalidade de ensino ao longo da sua história. Perpetuam-se ainda, nos anos 2000, as ações focais e em caráter de parceria, insuficientes para universalizar a educação básica no Brasil. Dessa forma, os programas apresentados, além de representarem expressões de uma política fragmentada para a educação da classe trabalhadora, apontam, em seu conteúdo, para a persistência do caráter seletivo do sistema educacional brasileiro, manten- 
do uma parcela significativa da população à margem do processo de escolarização, substituído por mecanismos de certificação.

O caráter utilitarista e empobrecido da concepção de educação proposta para os jovens e adultos brasileiros está amplamente coerente com a opção de sermos uma economia inserida no mercado mundial de forma associada e subordinada às nações centrais, posição que nos coloca predominantemente ligados às atividades econômicas neuromusculares ${ }^{17}$, as quais necessitam de pouco investimento em educação. Trata-se de uma concepção de educação para jovens e adultos trabalhadores restrita às necessidades do modelo societário do capital, que nos coloca, predominantemente, como consumidores e não como produtores de tecnologia.

Subordinadas à lógica de reorganização do capital, as propostas relacionadas à ampliação dos níveis de escolaridade dos trabalhadores têm servido:

1) para exercer funções de controle social, mediante o alívio à pobreza, revestindo-se, assim, de um caráter contenedor de insatisfações, proporcionando aparentes soluções dentro da ordem capitalista;

2) como fator de difusão dos valores relativos à competitividade, à empregabilidade e ao empreendedorismo, aos quais está subjacente a crença na individualização da problemática do desemprego e a transferência estrita, para o indivíduo, das iniciativas e responsabilidades referentes à sua situação no quadro societário;

3) à qualificação da maior parte da força de trabalho para exercício do trabalho simples.

O reconhecimento da EJA como modalidade de educação básica ganha espaço no plano formal, porém isto não tem sido traduzido no plano político concreto. Embora dados apresentados pelo MEC apontem para a ampliação do atendimento e para o aumentos no orçamento do MEC para EJA, a atuação do Governo Federal continua predominantemente centrada nos números grandiosos de um programa como o Brasil Alfabetizado, cujos resultados estão, como vimos, longe do anunciado. Essa constatação aponta para o fato de que não dispomos, até hoje, de políticas que superem ações de governo implementadas a partir de objetivos e critérios discutíveis e se

${ }^{17}$ Sobre essa questão, ver Arrighi, 1997. 
consolidem como políticas de Estado ${ }^{18}$. Estão, assim, longe de ser atingidos objetivos como a superação de déficits quantitativos e qualitativos da EJA nas redes públicas, bem como da necessária isonomia no que tange ao financiamento público das diversas modalidades e etapas da educação básica. Diante de tal quadro, o caráter de continuidade da lógica de subordinação é explícito, ao considerar que da mesma forma que o Programa Brasil Alfabetizado não rompeu com a histórica lógica de campanha, o Programa Fazendo Escola também não contribuiu para a necessária responsabilização do Estado (em seus três níveis) com a oferta de educação pública para todos.

Ao analisar as conexões estabelecidas pelos organismos internacionais entre educação, segurança e pobreza, Leher (1999) nos ajuda a compreender a lógica das políticas focais implementadas no Brasil. O autor destaca o fato de que essas encontram-se em pleno acordo com a idéia de que a educação contribui para a estabilidade política necessária à realização dos negócios; ou seja, para as condições de governabilidade necessárias à economia,

é visível a recorrência da questão da pobreza e do temor quanto à segurança: nos termos do presidente do Banco [Mundial], 'as pessoas pobres do Mundo devem ser ajudadas, senão elas ficarão zangadas' (CAUFIELD, 1996, p. 315). Em suma, a pobreza pode gerar um clima desfavorável para os negócios (p. 24).

Ainda segundo a argumentação de Leher, no mesmo trabalho, faz sentido que grande parcela da população tenha acesso apenas a rudimentos educacionais estreitamente relacionados ao desempenho de atividades no setor informal ou no subemprego, criando um "apartheid educacional".

$\mathrm{Na}$ realidade, destaca-se o papel regulador da educação, uma vez que, sob o imperativo de manutenção da ordem social, os programas educacionais, como os destacados neste artigo, se inscrevem na lógica de propiciar aos mais pobres alguma forma de uma pretensa "inclusão social". Especificamente, no que se refere às ações no âmbito da EJA, a estratégia de

${ }^{18}$ Proposição reafirmada no último Encontro Nacional de Educação de Jovens e Adultos (ENEJA). Ver: Relatório-síntese do VIII ENEJA. "EJA - uma política de Estado: avaliação e perspectivas". UFPE, Recife, 2006. 
gestão com base na focalização das ações de governo, no apelo ao voluntariado e na renúncia fiscal, faz-se presente, como destaca Oliveira (2003), "sobretudo nas políticas de financiamento, a partir da definição de custos mínimos assegurados para todos" (p. 24).

No processo de análise do movimento contraditório do real, faz-se necessário considerar a educação situada na materialidade da sociedade de classes, uma vez que na disputa político-ideológica "por qual escola" encontra-se, simultânea e dialeticamente, a disputa por qual sociedade. Consideramos que, a partir da análise empreendida, seja possível identificar razões estruturais que reiteram, sistematicamente, a subalternidade da educação de jovens e adultos trabalhadores.

Ao finalizar, entendemos ser importante destacar que as considerações aqui apresentadas não derivam da ingenuidade epistemológica que levaria a supor que o sistema-capital venha a promover a educação que efetivamente interessa aos trabalhadores e possa, assim, concorrer voluntariamente para a corrosão de suas próprias bases (RUMMERT, 1995). Conquistar essa educação é tarefa a ser enfrentada pela própria classe trabalhadora. Do mesmo modo, entendemos não constituir prática fecunda o mero "espetáculo da denúncia".

Entretanto, como sublinha Brunhoff, "embora tenhamos pouca audiência no momento atual, a análise crítica dos dogmas liberais deve continuar, tentando-se situá-la em relação àquilo que o autor percebe hoje das práticas sociais" (1991, p. 9). Se vivemos hoje tempos denominados neoliberais ou pós-modernos, isso não torna menos concreta, embora metamorfoseada, a máxima de Adam Smith (1983): "instrução para os trabalhadores, porém em doses homeopáticas". Consideramos, assim, que trazer à luz os simulacros que dão sustentação a esta realidade pode contribuir para um processo de construção de mudanças substantivas na vida da classe trabalhadora.

\section{REFERÊNCIAS}

ARRIGHI, G. A ilusão do desenvolvimento. Petrópolis: Vozes, 1998.

BRASIL. Lei de Diretrizes e bases da Educação Nacional. № 9.394 de dezembro de 1996. . Decreto n 2.208 de 17 abril de1997. 
. Parecer CNE/CEB n ${ }^{\circ} 11$ de 10 maio de 2000.

. Decreto no 5.154 de 23 julho de 2004.

. /IBGE (2006). Sintese de Indicadores Sociais 2006. Disponível em: <http://

www.ibge.gov.br/home/presidencia/noticias/noticia_visualiza.php?id_noticia=774>.

.FNDE. www.fnde.gov.br.

. FNDE. Resolução CD/FNDE nº 012, de 26 de abril de 2001.

. FNDE. Resolução CD/FNDE nº 025, 16 de junho de 2005.

. FNDE. Resolução CD/FNDE nº 022, de 20 de abril de 2006.

. FNDE. Resolução CD/FNDE nº 031, de 10 de agosto de 2006.

.www.fnde.gov.br/home/index.jsp?arquivo=/eja_edujovadult/eja.html.

. MEC. www.mec.gov.br.

. MEC. http://portal.mec.gov.br/secad/.

. UFF. www.uff.br/ejatrabalhadores.

BRUNHOFF, Suzanne de. A hora do mercado. Crítica do liberalismo. São Paulo: Unesp, 1991.

Folha Uol. http://www1.folha.uol.com.br/folha/educacao/ult305u19328.shtml.

Estado de São Paulo. http://txt.estado.com.br/editorias/2006/09/17/pol1.93.11.20060917.6.1.xml.

FRIGOTTO, G.; CIAVATTA, M.; RAMOS, M. A gênese do Decreto n. 5.154/2004: um debate no contexto controverso da democracia restrita. In: FRIGOTTO, G.; CIAVATTA, M.; RAMOS, M. (Orgs.). Ensino Médio Integrado: concepção e contradições. São Paulo: Cortez, 2005.

LEHER, R. Para fazer frente ao apartheid educacional imposto pelo Banco Mundial: notas para uma leitura da temática trabalho-educação. Trabalho e Crítica: anuário do GT Trabalho e Educação/ANPEd. Belo horizonte: NETE, n. 1, p. 16-29, set. 1999.

OLIVEIRA, D. A. Reformas educacionais na América Latina e os trabalhadores docentes. Belo Horizonte: Autêntica, 2003.

RODRIGUES, J. Ainda a educação politécnica: o novo decreto da educação profissional e a permanência da dualidade estrutural. Trabalho Educação e Saúde. Rio de Janeiro: Fundação Oswaldo Cruz, Escola Politécnica de Saúde Joaquim Venâncio, v. 3, n. 2, p. 259-282, set. 2005.

RUMMERT, S. M. Educação de adultos, trabalho e processos de globalização. Contexto e Educação, Ijuí / RS, v. 9, n. 39, p. 89-111, 1995. 
. Projeto Escola de Fábrica. Atendendo a pobres e desvalidos da sorte do século XXI. Perspectiva. Revista do Centro de Ciências da Educação. Universidade Federal de Santa Catarina. v. 23, n. 2, Florianópolis, jul./dez. 2005, p. 303-322.

. A Educação de Jovens e Adultos trabalhadores brasileiros no século XXI. O "novo" que reitera antiga destituição de direitos. Revista Sísifo. http://fpce.ul.pt , n. 2, 2007.

SMITH, A. A riqueza das nações: investigação sobre a sua origem e as suas causas. São Paulo: Abril Cultural, 1983.

SOARES. L. J. G. Educação de Jovens e Adultos. Rio de Janeiro: DP\&A, 2002.

VENTURA, J. P. O PLANFOR e a Educação de Jovens e Adultos Trabalhadores: a subalternidade reiterada. 2001. Dissertação (Mestrado em Educação) - Faculdade de Educação, Universidade Federal Fluminense, Niterói, Rio de Janeiro.

Texto recebido em 12 de nov. 2006 Texto aprovado em 15 de fev. 2007 